\title{
Emotions and Medicine
}

\section{What Do Patients Expect from Their Physicians?}

A ccording to the Global Burden of Disease Report, recently published by the World Health Organization, depression is currently the fourth leading cause of disability in the world. In the year 2020, depression will be second only to heart disease. ${ }^{1}$ Despite effective treatments, depression may often be unrecognized and untreated. ${ }^{2,3}$ Many persons in the community with depression see a general physician, ${ }^{4}$ so the primary care setting is pivotal when considering how to optimize treatment for depression and other forms of emotional distress in the community. But even if primary care physicians are prepared to provide "optimal treatment," are patients ready to accept it?

In this issue, Brody, Khaliq, and Thompson report patients' points of view about treatment by their personal physicians for emotional distress. ${ }^{5}$ The authors conducted two surveys of primary care patients. The first survey asked how important it was that physicians try to help with emotional distress. The second, smaller survey asked how physicians could help manage emotional distress, for example, through counseling, a drug prescription, or referral to a mental health professional. The surveys suggest that most patients, and especially patients with emotional distress and functional impairment, think that emotional distress is within the physician's purview. Most patients in this study preferred that the physician provide counseling, not drugs or referral. The implication is that patients would welcome inquiry about emotional distress and counseling about how to manage it.

I think the report by Brody and colleagues raises two questions. The first question is, "What is a case of psychiatric disorder in primary care?" Many surveyed patients who wanted the physician to help them with emotional distress did not meet standard criteria for major depression, nor did they meet a relaxed set of criteria for "minor" depression. Study limitations related to the assessment of clinical depression and to sampling issues may partially explain this finding. Nevertheless, it calls attention to a fundamental question-if patients seek care for mental distress but do not meet standard criteria, then how is a psychiatric disorder to be defined in primary care? Perhaps we need to develop a new classification system for mental distress in primary care. This classification system should recognize that the patient's own evaluation of functioning needs to be considered in formulating the therapeutic plan. ${ }^{6}$ Indeed, dealing with mental disorders in primary care may call for a new classification and approach to treatment. ${ }^{7}$ In the study by Brody and col- leagues, even for patients who met criteria of subsyndromal depression, the proportion who wished to receive help for emotional distress from the primary care physician was high. At the same time, more than one third of all patients did not think that it was at all important for the physician to try to help with emotional distress. Perhaps these findings indicate that the primary care diagnosis of mental distress involves the attitudes and beliefs of both patient and physician in a process of negotiation that occurs over time. This process may be neglected by studies that assess the patient at a single point in time, and could explain why these studies report poor rates of recognition by the physician.

Physicians can gauge the extent to which the patient is willing to discuss emotional distress by asking about functioning and stress in the patient's social and occupational roles. Patients who express emotional distress can then be more fully assessed, while other patients will give clear signals that emotional territory is not something they wish to cover. Much of this give-and-take probably depends on a stable and strong patient-physician relationship. Such relationships do occur in primary care but may have been eroded in recent years. Although physicians should be familiar with the diagnostic criteria for depression and anxiety used in psychiatric practice, ${ }^{8}$ many patients have discomfort that is not so easily characterized as all "body" or all "mind." One contribution of the article by Brody and colleagues is to remind us that patients with emotional distress perceive the value in receiving counseling from their personal physicians. We do not know the extent to which this perception reflects confidence in their physicians or the stigma and fear that patients associate with referral to a mental health specialist. This distinction remains an area for further exploration.

The second question raised by this report is, "Can primary care physicians provide treatment for depression and other forms of emotional distress given the constraints on their time and resources?" The report suggests that patients with emotional distress prefer counseling to medications. Significant barriers of time and resources, however, work against counseling in primary care, even when physician discomfort about dealing with mental disorders is surmounted. Despite the barriers, some patients get counseling from their primary care physicians. For example, in one study $61 \%$ of patients reported that their physicians helped them identify activities that made them feel better. ${ }^{9}$ In our study of the implementation of guidelines for managing depression in primary care settings, ${ }^{10,11}$ 
we gave physicians a broad view of what "counseling" means regarding depression treatment. In particular, we emphasized that counseling includes educating the patient about depression and about the medications sometimes used to treat depression, because these simple interventions improve adherence to pharmacotherapy. ${ }^{12} \mathrm{We}$ recommended that primary care physicians become familiar with at least one self-help manual, such as How to Heal Depression, ${ }^{13}$ or with the patient guide component of the guidelines. ${ }^{10,11}$ Nonpharmacologic interventions that are suitable for primary care settings are discussed at length in several excellent publications. ${ }^{14-17}$ Although physicians sometimes undervalue their role in patient education, patients express more satisfaction with medical care when information exchange takes place. ${ }^{18,19}$

Certainly, powerful disincentives, including the reluctance of some physicians and patients to deal with mental disorders and a managed care environment that often requires patients to be split into "medical" and "psychiatric" components, discourage counseling and other treatments for emotional distress in primary care settings. We must develop innovative ways to integrate primary health and mental health care, ${ }^{20,21}$ and accomplishing this goal will mean spending resources. Such an integration will require psychiatrists to think about the primary care setting without their preconceived notions from their experiences in specialty settings. I am a primary care physician, and I believe that most of my primary care colleagues want to care for their patients with emotional distress and do provide mental health care to them despite the barriers. ${ }^{22}$

We are rediscovering what Michael Shepherd concluded more than 30 years ago: the way to improve treatment for mental disorders in the community is to strengthen the therapeutic role of the generalist physician. ${ }^{23}$ The findings of Brody and colleagues reinforce the importance of the primary care setting for the evaluation and treatment of mental distress. Their findings also provide additional reasons for understanding how to help primary care physicians care for their patients' emotional distress.-JosePH J. Gallo, MD, MPH, The Johns Hopkins University School of Hygiene and Public Health, Baltimore, $M d$.

\section{REFERENCES}

1. Murray CJL, Lopez AD. The Global Burden of Disease: A Comprehensive Assessment of Mortality and Disability from Diseases, Injuries, and Risk Factors in 1990 and Projected to 2020. Cambridge, Mass: Harvard University Press; 1996.

2. Hirschfield RMA, Keller MB, Panico S, et al. The National Depressive and Manic-Depressive Association consensus statement on the undertreatment of depression. JAMA. 1997;277:333-40.
3. Higgins ES. A review of unrecognized mental illness in primary care: prevalence, natural history, and efforts to change the course. Arch Fam Med. 1994;3:908-17.

4. Gallo JJ, Marino S, Ford D, Anthony JC. Filters on the pathway to mental health care, II: sociodemographic factors. Psychol Med. 1995;25:1149-60.

5. Brody DS, Khaliq AA, Thompson TL. Patients' perspectives on the management of emotional distress in primary care settings. J Gen Intern Med. 1997;12:403-406.

6. Kravitz RL, Callahan EJ, Paterniti D, Antonius D, Dunham M, Lewis CE. Prevalence and sources of patients' unmet expectations for care. Ann Intern Med. 1996;125:730-7.

7. Goldberg D, Huxley P. Common Mental Disorders: A Bio-social Model. New York, NY: Tavistock/Routledge; 1992.

8. American Psychiatric Association. Diagnostic and Statistical Manual of Mental Disorders, DSM-IV. Washington, DC: American Psychiatric Association; 1994.

9. Robinson P, Bush T, Von Korff M, et al. Primary care physician use of cognitive behavioral techniques with depressed patients. J Fam Pract. 1995;40:352-7.

10. Depression Guideline Panel. Depression in Primary Care: Volume 1. Detection and Diagnosis: Clinical Practice Guideline, Number 5. Rockville, Md.: U.S. Department of Health and Human Services, Public Health Service, Agency for Health Care Policy and Research; 1993. AHCPR publication 93-0550.

11. Depression Guideline Panel. Depression in Primary Care: Volume 2. Treatment of Major Depression, Clinical Practice Guideline, Number 5. Rockville, Md.: U.S. Department of Health and Human Services, Public Health Service, Agency for Health Care Policy and Research; 1993. AHCPR publication 93-0551.

12. Lin EH, Von Korff M, Katon W, et al. The role of the primary care physician in patients' adherence to antidepressant therapy. Med Care. 1995;33:67-74.

13. Bloomfield HH, McWilliams P. How to Heal Depression. Los Angeles, Calif: Prelude Press; 1994.

14. Shearer SL, Adams GK. Nonpharmacologic aids in the treatment of depression. Am Fam Physician. 1993;47:435-43.

15. Brody DS, Thompson TL, Larson DB, Ford DE, Katon WJ, Magruder KM. Strategies for counseling depressed patients by primary care physicians. J Gen Intern Med. 1994;9:569-75.

16. Stuart MR, Lieberman JA. The Fifteen Minute Hour: Applied Psychotherapy for the Primary Care Physician. New York, NY: Praeger Publishers; 1986.

17. Stewart M, Brown JB, Weston WW, McWhinney IR, McWilliam CL, Freeman TR. Patient-Centered Medicine: Transforming the Clinical Method. Thousand Oaks, Calif: Sage Publishers; 1995.

18. Laine C, Davidoff F, Lewis CE, et al. Important elements of outpatient care: a comparison of patients' and physicians' opinions. Ann Intern Med. 1996;125:640-5.

19. Robbins JA, Bertakis KD, Helms LJ, Azari R, Callahan EJ, Creten DA. The influence of physician practice behaviors on patient satisfaction. Fam Med. 1993;25:17-20.

20. Ustun TB, Gater R. Integrating mental health into primary care. Curr Opin Psychiatry. 1994;7:173-80.

21. Falloon IRH, Fadden G. Integrated Mental Health Care: A Comprehensive Community-Based Approach. New York, NY: Cambridge University Press; 1993.

22. deGruy F. Mental health care in the primary care setting. In: Institute of Medicine. Primary Care: America's Health in a New Era. Washington, DC: National Academy Press; 1996:285-311.

23. Shepherd M, Cooper B, Brown AC, Kalton GW. Psychiatric Illness in General Practice. London, England: Oxford University Press; 1966. 